supply gas to the area boards, and gave the Council the duty of promoting and assisting the co-ordinated development of efficient and economical gas supplies. Part 2 was concerned with underground storage-Clause 4 prohibiting a gas authority from storing gas in natural porous strata underground without a storage authorization order from the Minister, thus giving the Minister an overriding control and a statutory obligation to safeguard the public as a whole and protect water supply. Clause 16 enabled the Minister to improve conditions on the development and operation of storage in the interests of safety and the protection of water resources. While the Bill was generally welcomed in the House of Commons, Mr. P. Jenkin questioned the appropriateness of various functions being performed by the Ministry of Power rather than by the Ministry of Housing and Local Government or the Ministry of Land and Natural Resources. He emphasized that, under a sub-section of Clause 4, the Minister had to take account of the desirability of preserving natural beauty, conserving flora, fauna, and geological or physio- graphical features of special interest, and of protecting buildings and other objects of architectural or historic interest. He did not think it wise that such responsibility should be concentrated in the Ministry responsible for technological advance, but this position was firmly defended by Mr. J. Morris, the Parliamentary Secretary to the Ministry of Power, in replying on the debate, who also explained that the Bill did not cover man-made structures, which were usually much smaller, and the authorities were usually able to purchase the necessary rights in the land. Rear-Admiral M. Giles and Mr. J. Payton stressed the importance of not proceeding faster with storage proposals than it was possible to carry public understanding and consent, and Mr. A. Palmer regretted that the Bill did not appear to envisage the industry as part of the fuel and power industry generally. The debate also ranged over various developments, such as the import of liquefied methane, the possibility of discovering gas under the North Sea, and their implications, which have led to the present situation.

\title{
METEOROLOGICAL SERVICES IN BRITAIN
}

\begin{abstract}
$\mathrm{N}$ the annual report on the Meteorological Office for 1963 *, the Director-General mentions two important events that took place during the year. The continued increase in the demand for computer services was taxing the capacity of the original high-speed computer Meteor, which by the end of 1963 was being used for an average of 85 hours a week. The decision was therefore taken to replace it by an English Electric 'Leo KDF' ' computing system, which is expected to come into service early in 1965. The greater speed and capacity of the new computer will enable the methods of numerical prediction to be used to produce short-term forecasts of the state of the middle and upper troposphere as a routine.

Secondly, the decision was taken to make available to the public the experimental 30-day forecasts of weather prospects, and these are now sent to subscribers at the beginning of each month under the title Monthly Weather Survey and Prospects, with a mid-monthly supplement. In support of the Branch responsible for the preparation of these forecasts, a new Branch was created to deal with the general problem of dynamical climatology and the mathematical analysis of the general circulation of the atmosphere.
\end{abstract}

The report follows the recent practice of providing an article on a special topic from each of the two Directorates. Climatological Services by the Director of Services gives not only an account of some of the services actually provided, but also an interesting description of the work involved in amassing the data required to answer the enquiries. We learn that there are about 100 Meteorological Office stations making observations four or more times a day, and some 500 'voluntary' stations making instrumental observations once a day. In addition, there are more than 6,000 voluntary rainfall observers who also make measurements once a day. The effort of detecting and correcting the errors and mistakes in the 1.6 million numbers that are dealt with every month will be considerably eased when the data can be processed by the new computer. It is surprising to learn that although marine climatological data have been available on punched cards since 1921, and upper air data since 1948, when such data became fairly widely available, land surface climatological data have only been put on to cards since 1957. Summaries of the data are published in the Monthly Weather Report and British Rainfall.

* Annual Report on the Meteorological Office for the year 1 January to 31 December 1963. (Met. 0. 756.) Pp. vili $+77+8$ plates. (London: H.M.S.O., 1964.) 6s. 6d. net.
This library of climatological data was used during 1963 to answer some 8,600 enquiries, nearly 30 per cent of which were classified as legal and agricultural, in nearly equal numbers. It is perhaps worthy of remark that most legal enquiries could be satisfied by a certified statement of the weather at "given times and places" chosen as the most likely to represent the actual conditions required. The remaining 6,000 queries answered by the Branch ranged from the provision of data for the design of industrial cooling towers, through the production of the meteorological sections of Sailing Directions (Admiralty Pilots) to the estimate of the maximum precipitation over the Blue Nile catchment for dam design.

The Director of Research provides an article on Climatic Variation, which includes a fascinating account of how Britain's summers and winters have altered over the centuries. Although it is known that the Earth is only just emerging from the last ice-age, the time-scales concerning the Meteorological Office only range from decades to centuries. The variations of climate even on this scale are vital near the limits of cultivation. Thus, in central Asia the average annual rainfall between 1900 and 1940 was double that about 1850 , and the yearly average has decreased greatly since 1940. Large changes in rainfall have also taken place on the edge of the Sahara and in eastern Australia. The temperatures prevailing in central England, produced by Prof. Manley under contract for the Meteorological Office, show a sharp rise from the very cold 1690 's to a short-lived warm period in the 1730 's and a gradual rise to the culminating warm period between 1920 and 1950 which has been unequalled in the past 600 years. Such changes are, moreover, not peculiar to Britain, and the deterioration that has apparently set in since 1940 is most marked around the Arctic Circle. It is clear that climatic changes can have a considerable effect on our habits and economy.

Work in the Meteorological Office has been directed towards producing maps of the average state of the wind patterns for each January and July back to 1750 . Thus, the mechanics of the general circulation of the atmosphere can be used to investigate the physical nature of climatic variation. Some interesting features have already been rovealed. The main currents of the average wind circulation in most parts of the world became stronger during the 200-year warming, and have paralleled the temperatures in reversing since 1930. The frequency of westerly winds over the British Isles has undergone similar changes, and in both respects the latest figures are 
comparable with the period before 1895. Secondly, the paths of Atlantic depressions moved northward as the warmest epoch of this century was approached, and are now reversing southward, giving eirculation patterns more analogous to those in the nineteenth century. These investigations also promise to assist the experiments in long-range weather forecasting.

The remainder of the report consists of a brief summary of the work of each Branch, notes on the weather of 1963 , a large number of statistics relating to the Services Directorate, and details of international commitments undertaken by members of the Office.

By its very nature the report can only deal with the work actually carried out by the Meteorological Office during the year. Any review, however, must be expected to comment not only on what has been done but also on what has been left undone, or at least unsaid. There is, for example, no indication that radar is being used operationally in any way by the Office. Radar is an instrument with the ability to detect precipitation, and although the interpretation is not easy, it ce $e^{-}$provide both qualitative and quantitative information. 'Thus, radar has been used in the United States to estimate areal rainfall and hence to predict river-levels in many drainage basins whenever there is a flood risk, with consistently good results.

Here, however, the Meteorological Office is only considering the problem of river flood prediction ly constructing maps of estimated soil water deficit. While the possibility of using radar observations of precipitation distribution for short-period forecasting may not be established, surely any forecast for a few hours ahead would be assisted by patterns of the actual rain areas from hour to hour, which could be simply provided by a few correctly sited high-powered $10-\mathrm{cm}$ radars.

A more fundamental criticism can perhaps also be made. During recent years the Meteorological Office has brought itself closer to the public by the provision of weather information centres in four big cities and by maintaining contact with research and advisory workers in agriculture. There is, however, no evidence in this report that the Office is making any strong attempt to explore its further potential for the provision of services to the community. While the Research Directorate may justifiably exist purely to advance our knowledge of meteorology, any advances should be used to enable new, better or more reliable information to be given to those who require it, or who, if shown, might find it to be applicable. Yet if the significance of any new facilities, or even existing ones, is not impressed on the public, it cannot be expected to use the services of the Office correctly or fully. It may be, as the Director-General mentions, that the resources of the Office are being stretched to meet the large and only partially satisfied demands for information about weather and climate. Some redeployment may thus be called for within the Office, and one may even wonder whether the community would be better served by a meteorological service which is not a State monopoly, as is the case in some other parts of the world. J. R. Probert-Jones

\section{THRIPLOW MEADOWS MANAGEMENT EXPERIMENT}

$\mathrm{W}$ ET meadows, which were once used for rough grazing or mowing, have been disappearing in recent years at an alarming rate from many English counties. Modern farming practice has no place for such fields. Yet, in the past, they have carried a rich flora and fauna, and without them the English countryside would be gravely impoverished for the naturalist. Among the plants especially associated with wet meadows, the marsh orchids (Dactylorchis spp.) are particularly striking, often occurring in large numbers. One such population is well known to Cambridgeshire botanists around a stream near Thriplow on the estate of Lord Walston of Newton Hall. Here, in favourable seasons, thousands of handsome flowering spikes, mainly Dactylorchis praetermissa, can be seen in the roughly-grazed meadows.

In 1961 Lord Walston leased a small meadow within the orchid area for seven years to the Cambridgeshire and Isle of Ely Naturalists' Trust. 'This body successfully applied to the Nature Conservancy Board for a grant of $£ 250$ over five years to enable it to carry out a simple experiment in management of the meadow. The aim of the experiment was to determine the conditions of mowing or grazing under which the orchid populations were maintained or extended, so that it would be possible to recommend management procedure in cases where the Trust might have opportunities of protecting such communities. The work is described by G. Crompton and S. M. Walters in the 1964 Handbook* of the Society for the Promotion of Nature Reserves.

Until ten years ago, the meadow had been regularly grazed by cows. After this, cattle were grazed for six weeks at the end of each year, and for the past two years there was no grazing at all. With this diminution of grazing, Carex acutiformis increased considerably.

It was decided that, for experimental purposes, the meadow should be divided into four approximately equal

* Society for the Promotion of Nature Reserves. Handbook 1964 Forty-Seventh Annual Report, year ending 31st March, 1964. Pp. 56+ plates. (London: The Society for the Promotion of Nature Reserves, British Museum (Natural History), 1964.) 10s. areas: Strip 1 to be grazed by horses, Strip 2 to be cut annually, Strip 3 to be the control, and Strip 4 to be grazed by cows. During the summer, and before the strips were cut, a rough sketch plin of the dominant vegetation was made. There are twel-re wet hollows in the meadow and their position was noted; a list has been made for each hollow of the interesting and dominant plants present.

By the end of the 1963 season the five-year experiment was at a half-way stage. Modifications to the original plan of grazing Strip 1 with horses and Strip 4 with cows were necessitated by practical difficulties. Records were prepared of the orchid population at the end of June each year by a volunteer party which counted the flowering spikes on each strip. The results are summarized as follows:

\begin{tabular}{crcr} 
Strip & $\underline{1961}$ & $\underline{1962}$ & 1963 \\
\hline 1 & 1,047 & 1,516 & 2,049 \\
2 & $486^{*}$ & 409 & 658 \\
3 & $693^{*}$ & Not counted & 498 \\
4 & $c .250^{*}$ & 716 & 1,281
\end{tabular}
15.

* Probably underestimated because these strips were counted late--July

The figures, although incomplete, are revealing. In Strip 1 the initially high orchid population had almost doubled by 1963; in Strip 4 there was a significant increase. Rough grazing, whether by horses or cattle, was favourable to the orchid population-or at least to their free flowering. There is some evidence that the flower-spikes are avoided by the grazing animals, presumably because they are unpalatable. Cutting in August (Strip 2) did not diminish the flowering orchids, though there was no significant increase. It is only in the uncut and ungrazed control (Strip 3) that a decrease in flowering was evident. This is not surprising: over more than half the area of Strip 2 there is now a rank growth of $C$. acutiformis, with which few other species can effectively 